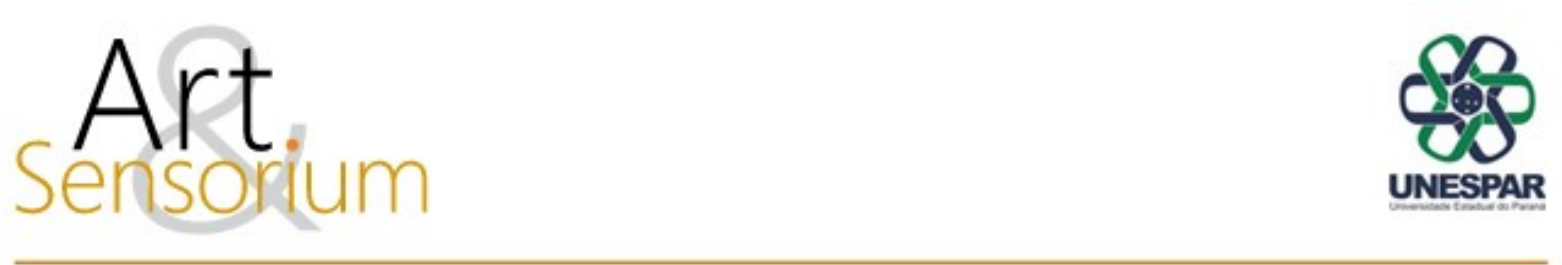

\title{
A LEITURA DE VISUALIDADES INDÍGENAS POR MEIO DO GRAFISMO GUAJAJARA: NOTAS PRELIMINARES PARA INTERPRETAÇÃO
}

https://doi.org/10.33871/23580437.2021.8.1.153-166

\author{
Andréa Lima Barros ${ }^{1}$ \\ Bruno de Oliveira da Silva ${ }^{2}$ \\ Elloane Carinie Gomes e Silva ${ }^{3}$
}

\section{Resumo}

Este trabalho faz referência ao povo indígena Guajajara-Tenetehara, pertencente ao tronco linguístico tupi-guarani e que habita aldeias estabelecidas em vários municípios do Maranhão, principalmente às margens dos rios Corda, Mearim e Pindaré. A arte gráfica do grupo é um elemento expressivo de seus significados social, espiritual e identitário, estando conectada a um complexo sistema representativo e conceitual. Esta pesquisa propõe a leitura de elementos que permeiam seus grafismos com a intenção de refletir sobre características socioculturais e ontológicas no contexto amazônico, bem como compreender alguns marcadores de identidade étnica. A partir da abordagem qualitativa com objetivos exploratório-descritivos e interpretativos, são conduzidas as pesquisas bibliográfica e documental. O estudo em campo subsidiou o desdobramento das análises e concepções subjacentes que convergiram para marcadores visuais capazes de apontar atributos conectados à um vasto acervo de práticas culturais do povo Guajajara.

Palavras-chave: Arte gráfica; pintura corporal indígena; Guajajara-Tenetehara; material visual.

\footnotetext{
${ }^{1}$ Bacharela em Administração, especialista em Propaganda, Publicidade e Marketing e em Jornalismo e Marketing Político pelo Centro de Ensino Unificado de Teresina (CEUT). Mestra e Doutora em Turismo e Hotelaria pela Escola de Artes, Comunicação e Hospitalidade da Universidade do Vale do Itajaí (UNIVALI). Desenvolve pesquisas na área do turismo, cultura e desenvolvimento local e regional. ORCID: https://orcid.org/0000-0003-2786-0759. Lattes: http://lattes.cnpq.br/5534851813690592. E-mail: andrea.barros@ifma.edu.br.

2 Fotógrafo e pesquisador, possui Licenciatura em História pelo Centro Universitário Internacional de Curitiba (UNINTER). Bacharel, Mestre e Doutorando em Turismo e Hotelaria pela Escola de Artes, Comunicação e Hospitalidade da Universidade do Vale do Itajaí (UNIVALI). Pós-graduando em Artes (Lato Sensu) pela Universidade Federal de Pelotas (UFPel). Pauta-se nas conexões transdisciplinares de sua formação para desenvolver estudos visuais, tendo como principais objetos: produções fotográficas e fílmicas, analisando as significações entre a História, Arte e Turismo na sociedade e suas implicações culturais. ORCID: https://orcid.org/0000-0002-5811-0689. Lattes: http://lattes.cnpq.br/8298852539612815. E-mail: portalbruno.oliveira@gmail.com.

${ }^{3}$ Designer de produto. Doutoranda em Desenvolvimento Sustentável do Trópico Úmido pelo Núcleo de Altos Estudos Amazônicos (NAEA) da Universidade Federal do Pará (UFPA). Dedica-se a pesquisas interdisciplinares nos campos do Design, Arte e Patrimônio Cultural, investigando os objetos oriundos de expressões artístico-culturais das populações tradicionais amazônicas em distintos processos de significação, comunicação e interpretação. ORCID: https://orcid.org/0000-0002-5163-6311. Lattes: http://lattes.cnpq.br/8046518595253766. E-mail:
} elloane.carinie@gmail.com. 


\title{
THE READING OF INDIGENOUS VISUALITIES THROUGH GUAJAJARA GRAPHICS: PRELIMINARY NOTES FOR INTERPRETATION
}

\begin{abstract}
This paper refers to the Guajajara-Tenetehara indigenous people, a branch in the TupiGuarani linguistic family. It inhabits villages established in many Maranhão State regions, mainly on the Corda, Mearim, and Pindaré bank rivers. The group's graphic art is an expressive element of its social, spiritual, and identity meanings connected to a complex representative and conceptual system. This research proposes the reading of elements that permeate the graphics, intending to reflect on socio-cultural and ontological characteristics in the Amazon context and understand some markers of ethnic identity. The bibliographic and documentary research were conducted from a qualitative approach with exploratory-descriptive and interpretive objectives. The study supported the unfolding of the analyses and underlying concepts that resulted in visual markers capable of pointing out attributes connected to a vast collection of the Guajajara group's cultural practices.
\end{abstract}

Keywords: Graphic art; indigenous body painting; Guajajara-Tenetehara; visual material.

\section{LA LECTURA DE VISUALIDADES INDÍGENAS A TRAVÉS DE LOS GRÁFICOS GUAJAJARA: NOTAS PRELIMINARES PARA LA INTERPRETACIÓN}

Resumen: Este trabajo hace referencia al pueblo indígena Guajajara-Tenetehara, perteneciente al tronco lingüístico tupi-guaraní y que habitan en aldeas establecidas en varios municipios de Maranhão, principalmente en las orillas de los ríos Corda, Mearim y Pindaré. El arte gráfico del grupo es un elemento expresivo de sus significados sociales, espirituales e identitarios, al estar conectado a un complejo sistema representativo y conceptual. Esta investigación propone la lectura de elementos que impregnan sus gráficos con la intención de reflexionar sobre características socioculturales y ontológicas en el contexto amazónico, así como comprender algunos marcadores de identidad étnica. Con base en el enfoque cualitativo con objetivos exploratorio-descriptivos e interpretativos, se realiza una investigación bibliográfica y documental. El estudio de campo proporcionó el despliegue de los análisis y conceptos subyacentes que convergieron en marcadores visuales capaces de señalar atributos relacionados con una vasta colección de prácticas culturales del pueblo guajajara.

Palabras claves: Arte gráfico; pintura corporal indígena; Guajajara-Tenetehara; material visual.

\section{Introdução}

As artes indígenas fazem parte das experiências de uma sociedade na qual são conectadas por distintas esferas da cultura como a organização social e o sistema de crenças, as possibilidades e limitações do ambiente/natureza, a tecnologia disponível para o grupo, entre outras (VIDAL, 1985). A qualidade estética constitui para os povos indígenas a natureza ou essência de sua própria humanidade, assim como um meio para o armazenamento e transmissão de informações compartilháveis segundo uma lógica compreendida pelo artista e grupo ao qual pertence (VELTHEM, 2010).

Dentre as expressões artísticas existentes, os grafismos permeiam diferentes suportes como os corpos humanos, artefatos e moradias - e são executados por meio da pintura, gravura e tecelagem (LAGROU; VELTHEM, 2018). Tal elaboração plástica, tomada em sentido amplo, constitui uma intervenção técnica e simbólica dotada de sentido decorativo e que objetiva a impressão de determinada marca social em pessoas e artefatos, pois cada povo indígena desenvolve um "estilo 
próprio" (VELTHEM, 2010, p. 60). Entre o povo Guajajara os padrões gráficos estão conectados a um complexo sistema representativo e conceitual com predominância de formas geométricas e desenhos em alusão à biodiversidade, assim como a utilização de corantes naturais para a pintura corporal (BARROS, 2019).

É importante explanar que os Tenetehara, pertencentes ao tronco linguístico tupi-guarani, ocupam vários municípios maranhenses, principalmente as margens dos rios Corda, Mearim e Pindaré, sendo conhecidos como Guajajara; no estado do Pará eles estão às margens dos rios Gurupi, Guamá e Capim, sendo conhecidos como Tembé. Pelas semelhanças linguísticas e culturais, além do estabelecimento de muitos intercâmbios entre os dois grupos, a hipótese de que descenderiam de uma única sociedade é coerente (NEVES; CARDOSO, 2015), contudo, ambos se identificam como povos distintos (BARROS, 2019).

Diante do exposto, esta pesquisa propõe a leitura de elementos que permeiam a arte gráfica do povo Guajajara-Tenetehara do Maranhão com a intenção de refletir sobre características socioculturais e ontológicas no contexto amazônico, bem como compreender alguns marcadores de sua identidade étnica. Trabalhos etnográficos e antropológicos que abordam distintas perspectivas de estudo acerca do povo Guajajara, como os de Wagley e Galvão (1961), Zannoni (1999), Neves e Cardoso (2015) e Oliveira (2019) auxiliaram na construção das interpretações do conteúdo gráfico apresentado neste trabalho, uma vez que não foram encontrados - nos portais de pesquisa científica ${ }^{4}-$ levantamentos sobre os grafismos que compõem a tradição criativa do grupo.

Os estudos acerca das artes gráficas identificadas na literatura, em sua maioria, centram-se no povo Tembé-Tenetehara do Pará; por sua vez, os estudos acerca da sociedade Guajajara estão voltados para questões históricas de formação social e ocupação territorial, bem como discussões relacionadas a sua cosmologia e os fenômenos de mudanças culturais. Dada a relevância de se estabelecer um entendimento acerca da arte gráfica dos Guajajara, este trabalho surge com reflexões preliminares para a sua interpretação, fornecendo subsídios para estudos mais amplos acerca de processos de significação e fortalecimento da identidade étnica do grupo ${ }^{5}$.

A partir da abordagem qualitativa com objetivos exploratórios, descritivos e interpretativos, são conduzidas as pesquisas bibliográfica e documental que versam sobre a antropologia estética e etnografia, com ênfase nos trabalhos de Lagrou $(2010,2018)$, Velthem $(2010,2018)$ e Vidal (1985, 2000), em especial na analítica de Severi e Lagrou (2013) acerca dos grafismos e figurações indígenas, onde é dada uma atenção particular à relação entre ritual e criação artística na qual a imagem surge como instrumento de mediação do mundo fenomenológico.

A análise centrou-se na composição de elementos formais dos grafismos utilizados pelos Guajajara na pintura corporal. Desta forma, o estudo em campo trouxe os registros de alguns desses padrões gráficos para o desdobramento da análise e concepções subjacentes provenientes de uma imersão na realidade da Aldeia Zutiwa, localizada na reserva indígena Araribóia, no município de Arame (MA). Tal experiência investigativa combinou distintas técnicas, a saber, a aplicação da observação sensitiva, mapa mental, grupo focal e entrevistas semiestruturadas com um grupo de voluntários e pessoas indicadas pelo líder da aldeia. O registro e as capturas foram realizados pelos próprios respondentes da pesquisa, também como proposta de se deixar ver pelos olhos de quem se pinta não como adereço, mas como mística pessoal de convívio social.

De modo geral, o estudo de materiais visuais de povos indígenas permite o detalhamento de manifestações estéticas e simbólicas centrais para a compreensão dessas sociedades, fornecendo

\footnotetext{
${ }^{4}$ Foram realizadas pesquisas nos portais Ebsco host, Scielo, Periódicos Capes e repositórios eletrônicos do Museu Paraense Emílio Goeldi e do Instituto Nacional de Pesquisas da Amazônia.

${ }^{5}$ De grande importância, o fortalecimento da identidade étnica implica no combate a invisibilidade ocasionada pela falta de políticas públicas eficientes que solucionem os desafios de manutenção e defesa do território Guajajara em razão dos conflitos com madeireiros e grileiros na região (BETIM, 2019).
} 
subsídios para discussões mais profundas, em especial no campo da educação, acerca de questões ambientais, históricos, direitos humanos, diversidade étnica e visibilidade de tradições culturais (VIDAL, 2000), o que pode contribuir ainda para o fortalecimento de comunidades indígenas (VELTHEM, 2010). Neste contexto, as visualidades são entendidas, em certo sentido, como as possibilidades de "expansão visual" da decoração dos corpos indígenas, para que sejam percebidos os "aspectos ocultos da visão ordinária" por meio dos grafismos (VELTHEM, 2010, p. 63). Em vista disso e focalizando elementos da arte gráfica do povo Guajajara serão apresentados a partir de agora algumas abordagens relevantes acerca das artes indígenas e, na sequência, têm-se os caminhos de interpretação de seu conteúdo.

\section{Artes indígenas}

As sociedades indígenas não partilham a noção de arte e estética tal qual a tradição históricofilosófica ocidental, contudo isso não significa que elas não tenham formulado seus próprios termos e critérios para distinguir e produzir beleza, ou mesmo articular apreciações qualitativas de uma fruição estética (LAGROU, 2010). A arte produzida por diferentes grupos indígenas partilha, com outros componentes culturais, um modelo de experiência coletiva e participa da definição de pessoas, assim como de suas relações e produções; portanto, não existe uma arte comum e geral, pois cada povo desenvolve um estilo próprio (VELTHEM, 2010).

As tradições artísticas indígenas se caracterizam pela permanência, como os registros rupestres pintados ou gravados em abrigos ou afloramentos rochosos, passíveis de serem encontrados em praticamente todo o território nacional (PESSIS, 2004). A universalidade dessa atividade não ligada às técnicas de subsistência denota a sua importância sociocultural no desenvolvimento das sociedades (PESSIS; GUIDON, 2000). Os referidos registros são as primeiras manifestações estéticas de grupos remotos do Brasil, especialmente rica e documentada na região Nordeste e estudada como um meio de comunicação entre os povos ágrafos, como marcadores de memória, fronteiras culturais ou políticas indicadoras de etnias diversas (MARTÍN; ASÓN, 2019).

Essa identidade gráfica permite o reconhecimento da identidade cultural do grupo, entendida na pesquisa histórica como um conceito que se traduz no coletivo geral - conjunto de elementos característicos pelos quais ela pode ser conhecida e diferenciada de outras -, e no subcoletivo, um plano mais particular onde existem semelhanças com os elementos característicos da identidade coletiva, mas também existem outros elementos de diversidade que são próprios (PESSIS; CISNEIROS; MUTZENBERG, 2018). Assim, a "faculdade estética" é inata aos indivíduos, é algo tão natural como o falar ou qualquer outra expressão de atividade cognitiva (VIDAL, 1985).

A experiência estética indígena está conectada a variadas formas, desde a produção de objetos para uso doméstico, ritualístico e ferramentas de trabalho, composições de pinturas corporais, produção do espaço, música, dança e domínios da oralidade. Assim, entende-se que na vida indígena a arte expressa um conhecimento que é material, técnico e prático e é exercido em diversos campos de criação e utilização de obras produzidas (LAGROU; VELTHEM, 2018). As artes indígenas se revestem antes de particularidades expressivas e a experiência estética constitui elemento fundamental na transmissão de conhecimentos e valores sociais (VELTHEM, 2010).

A arte gráfica é uma expressão em particular, pois permeia diferentes suportes como os corpos humanos, artefatos e moradias - e é executada por meio da pintura, gravura e tecelagem (LAGROU; VELTHEM, 2018). Os grafismos marcam o estilo de diferentes grupos indígenas, pois são materializações densas de redes de interações complexas que supõem conjuntos de significados (LAGROU, 2010), sendo um deles, por exemplo, a utilização de padrões gráficos como forma de expressão complementar à tradição oral, que designa no sentido estrito a "arte da palavra numa sociedade", e no sentido mais amplo é "geradora e formadora de um tipo particular de homem e de sociedade" (FREIRE, 1992, p. 19). 
Dentro da historiografia, as representações gráficas indígenas dizem respeito "[...] à vida em sociedade, ao modo como os indivíduos são classificados e como devem ou podem se relacionar entre si, com a natureza e com o cosmo" (VIDAL, 2000, p. 284). Deste modo, os métodos das artes indígenas não permitem a sua compreensão apenas como encadeamento de formas, mas antes como um mecanismo cognitivo de ordenamento e definição do universo social e o não social, o humano e o não humano, acarretando o desenvolvimento de um estilo peculiar a cada povo (VELTHEM, 2010). Em uma perspectiva ampla, a arte ameríndia leva ao extremo a tensão entre imagem material e imagem mental, culminando em grafismos que tendem a uma abstração que oculta uma figuração virtual. $^{6}$

Nesta lógica, Velthem (2010, p. 61) sintetiza que as artes indígenas modelam uma visão muito específica e podem se apresentar culturalmente densas, assim, “[...] uma máscara ou grafismo que possua características antropomorfas não representa, necessariamente, um ser humano específico, mas remetem a concepções subjacentes acerca da humanidade", paralelamente, algumas formas gráficas podem parecer abstratas, mas configuram representações iconográficas, isso significa que há elementos, entre o modelo e representação, que podem ser reconhecidos pelo produtor e seus pares comunitários, o que leva a compreensão de que em algumas sociedades indígenas, o papel dos grafismos é o de transmitir simultaneamente a percepção sintética de múltiplas realidades.

\section{O povo Guajajara do Maranhão}

No início do século XVII, cerca de 250.000 pessoas habitavam a região onde se localiza hoje o estado do Maranhão. Faziam parte dessa população cerca de 30 etnias diferentes - algumas já extintas ou em processo de autodeclararão, como os Barbados, Amanajós, Araioses, kapiekrã -, das quais se encontram hoje os Krikati, Canela, Guajaja-Tenetehara e Gavião (SCHRODER, 2002). Via de regra, os povos indígenas são classificados por semelhanças na língua praticada, na região do Maranhão existem dois troncos linguísticos: Tupi-Guarani e Macro-Jê. Os povos Guajajara, Awáguajá, Urubu-Kapor são de língua tupi, enquanto os povos Canela Apaniekrá e Ramkokamekra, Pukobyê (gavião), Krikati e Timbira Krepu'Kateyé são falantes da língua Jê (BARROS, 2019).

As semelhanças apresentadas pelos falantes de línguas pertencentes ao mesmo tronco linguístico expressam as modalidades de sua organização sociocultural. Os Guajajara-Tenetehara constituem a etnia mais numerosa do Maranhão e representa um dos poucos remanescentes dos povos tupiguarani que se distribuíram pelo extenso território brasileiro (BARROS, 2019). Eles ocupam vários municípios maranhenses, principalmente às margens dos rios Corda, Mearim e Pindaré; no estado do Pará eles estão situados às margens dos rios Gurupi, Guamá e Capim (ISA, 2020). Atualmente faltam estatísticas sobre o (de)crescimento da população Guajajara-Tenetehara e as taxas de mortalidades infantil e adulta (IBIDEM).

A palavra "Tenetehara" significa "ser íntegro" o "homem verdadeiro", no Maranhão esse povo é conhecido como Guajajara e, no Pará, como Tembé - como mencionado no início do texto. Com base em estudos de linguística, os Tembé já não se comunicam com os Guajajara e não compartilham os mesmos ritos, assim, o que os une é a identidade de origem Tenetehara, mas as suas línguas, por exemplo, se encontram em um processo crescente de diferenciação, embora possuam afinidades e semelhanças (SILVA, 2010). O território habitado pelos Guajajara integra, por sua ecologia, o bioma amazônico. As terras indígenas são cobertas pelas florestas altas da Amazônia e por matas de cerradão mais baixas. $^{7}$

\footnotetext{
${ }^{6}$ Conceito que se refere a imagem mental que não é dada a ver nos desenhos, mas pode ser vislumbrada e/ou fortemente sugerida para quem está preparado e em circunstâncias específicas (SEVERI; LAGROU, 2013).

${ }^{7}$ Matas de transição entre as florestas amazônicas e o cerrado (ISA, 2020).
} 
Os estudos em campo revelaram alguns aspectos das formas de vivência do povo Guajajara, a saber, a sua alimentação é proveniente da agricultura de subsistência e pesca (mais praticada pelas aldeias ribeirinhas), sendo a caça uma prática cotidiana, porém esporádica devido à escassez (BARROS, 2019). Como característica dos grupos de floresta tropical, os Guajajara se dedicam ainda à coleta $\mathrm{e}$ extração de produtos naturais como mandioca, milho, feijão, batata, frutas e algumas hortaliças, no entanto, tais atividades estão sendo substituídas pela fruticultura e pelos alimentos processados e industrializados que agora chegam com mais facilidade às comunidades indígenas.

Comumente, os trabalhos etnológicos abordam o contato interétnico entre os Guajajara e os nãoindígenas, enfatizando os movimentos históricos de mudanças culturais ocasionados pela convivência com os "caboclos"8 ou diferentes tribos localizadas na mesma região rural. Neste ínterim, os fenômenos de aculturação ${ }^{9}$ e os reflexos do contato com as instituições de âmbito nacional, como a Fundação Nacional do Índio - FUNAI, se tornaram um caminho para o estudo da sociedade Guajajara-Tenetehara, em específico, o modo com que suas tradições reagem às condições do ambiente onde se desenvolvem. ${ }^{10}$

No que tange a organização familiar, a unidade mais importante da estrutura social do povo Guajajara é a família extensa, constituída por um número de famílias nucleares. Em geral, novas aldeias são criadas pela migração de uma família extensa que por algum motivo precisou abandonar a moradia anterior. As aldeias variam de tamanho em razão da quantidade de famílias que nelas habitam; assim, as habitações são distribuídas em ruas de traçados desiguais, semelhantes aos povoados do interior do Maranhão. Nas proximidades de cada aldeia existem os "centros", que são abrigos temporários localizados junto às roças e onde geralmente estão instaladas as casas de farinha.

Historicamente, as experiências escolares nas aldeias tiveram início com as missões jesuíticas, no século XVII, e capuchinos a partir do século XIX. Atualmente, as escolas contam com professores indígenas e não-indígenas, sendo a prática do ensino bilíngue restrita a algumas aldeias em virtude da falta de material didático e qualificação docente para o magistério indígena (PIB, 2020). Em específico, na aldeia Zutiwa existe ensino bilíngue com atividades que incluem as oficinas de pintura corporal e artesanato, esta conforma aproximadamente 80 (oitenta) famílias e se caracteriza por uniões entre indígenas e não-indígenas. A Figura 01 apresenta a situação geográfica da aldeia Zutiwa, local onde foi realizada a pesquisa de campo para este trabalho.

\footnotetext{
${ }^{8}$ Termo de uso recorrente na região amazônica, serve para designar uma população "mista", descendente da fusão entre brancos, africanos e indígenas (WAGLEY; GALVÃO, 1961, p. 182).

9 A "aculturação" pode ser entendida como a assimilação de traços ou elementos de uma cultura por outra, em um processo de readaptação e modificação para que sejam harmonizados em sua estrutura íntima. No entanto, esse "empréstimo" de traços culturais só acontece quando existe algo que o favoreça e corresponda a uma necessidade adquirida (IBIDEM, p. 11)

${ }^{10}$ O estudo clássico de Wagley e Galvão (1961) chamou a atenção para uma "cultura em transição" dos Tenetehara, convergindo documentos históricos e registros da pesquisa em campo ao processo e características de contato interétnico desta sociedade. Embora tenha gerado controvérsias com o prognóstico de transformação dos Tenetehara em caboclos no espaço de uma geração ou mais, as discussões serviram como base para pesquisas subsequentes acerca da evolução de tradições histórico-culturais do grupo (IBIDEM, p. 10).
} 

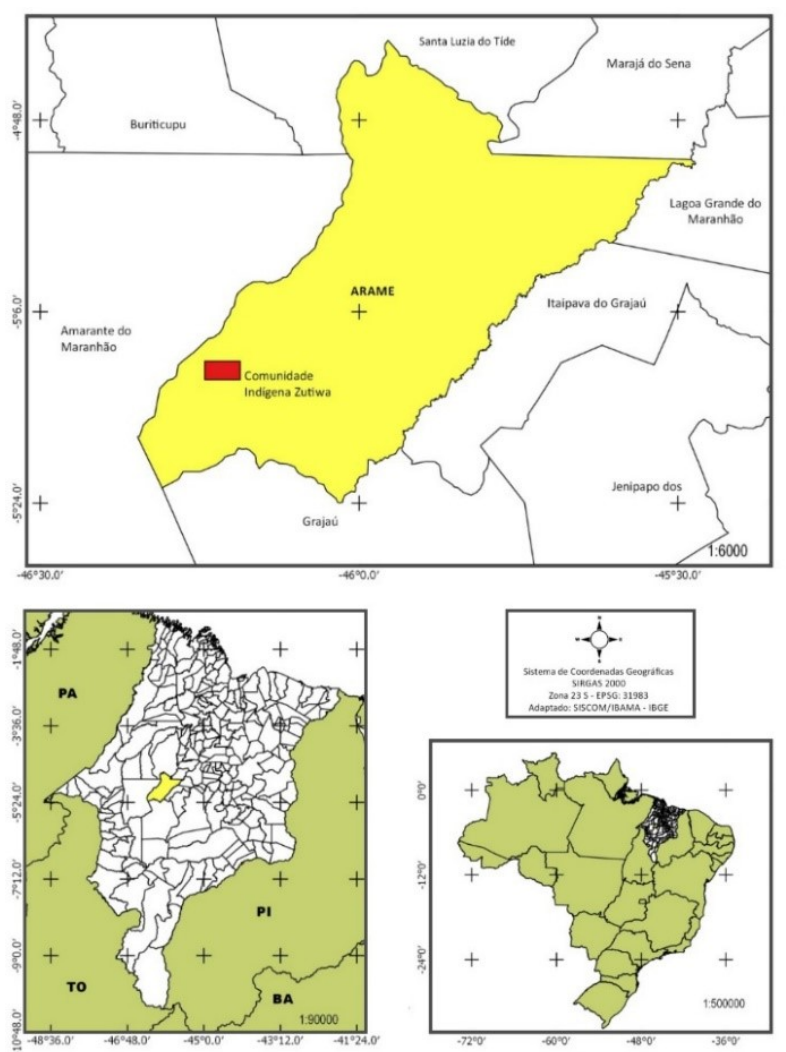

Figura 01 - Situação geográfica da aldeia Zutiwa. Fonte: Elaboração própria (2021).

Nas observações registradas na aldeia Zutiwa, foi identificado que os indígenas sentem e percebem os códigos e significados culturais de seu povo e sabem que esses os diferenciam de outros grupos (BARROS, 2019). Assim, foi possível perceber um conjunto de valores culturais em uma experiência permeada por visões de mundo perenizadas por fontes mnemônicas, dentre elas, a arte gráfica em corpos, um dos elementos mais expressivos do significado social, espiritual e identitário dos Guajajara dessa região.

\section{Grafismos do povo Guajajara}

Durante a condução da pesquisa foram reportados cerca de quatro padrões distintos para a composição dos motivos decorativos para o corpo: pontos, linhas retas, figuras geométricas e traços representando a pele de cobra e casco de jabuti. Os registros limiares de Wagley e Galvão (1961) acerca da tradição criativa na sociedade Tenetehara sintetizam o uso de motivos geométricos à representação naturalística de animais. Os componentes gráficos apresentam características cromáticas e iconográficas, existindo diferenças entre a aplicação no suporte humano e os que aparecem nos artefatos, em ambos, são utilizadas técnicas e materiais variados de base vegetal.

Inicialmente é oportuno discorrer sobre os aspectos relacionados ao uso de tinturas vegetais para as pinturas corporais. A matéria-prima central utilizada pelo povo Guajajara para a aplicação dos grafismos é a tinta oriunda do fruto do jenipapeiro (genipa americana), conhecido popularmente como jenipapo. Para extrair o pigmento preto-azulado os indígenas ralam o fruto e extraem um caldo que, exposto ao sol, em pouco tempo servirá como tinta (SÁ; SILVA, 2017). Utiliza-se ainda a tinta extraída do fruto avermelhado da planta "bixa orellana", de onde é obtida a cor rosada conhecida como "urucum" ou "urucu" e as enzimas de algumas árvores para pigmentar em tons mais escuros a nódoa na pele. 
Convergindo estudos etnográficos, desenvolvidos no interior das sociedades Tenetehara na região amazônica, foi inferido que a utilização da tinta do jenipapo é uma de suas principais singularidades justificada pela questão geográfica, pois "nas regiões sul e sudeste do Brasil, em função do clima, não há jenipapo e as sociedades que vivem lá, atualmente, não fazem a pintura corporal com este tipo de tinta" (NEVES; CORRÊA, 2011, p. 19). Uma outra questão é a sua predominância como significado na pintura corporal dos Tenetehara em relação ao uso do urucum/urucu que é predominante na família Jê, como os Gavião (SÁ; SILVA, 2017, p. 107).

O plano cosmológico dos Guajajara-Tenetehara serve como instrumento de compreensão do significado dos elementos que compõem seus desenhos uma vez que a relação entre a arte gráfica e a interpretação das narrativas míticas é capaz de revelar inúmeros aspectos do ethos de uma sociedade de onde elas provêm (TOCHETTO, 1996, p. 33). Como exemplo, para os Tenetehara a explicação da origem e uso do jenipapo é mitológica, nos tempos ancestrais ele era um homem com poderes mágicos que mudava a vida das pessoas e quando morreu se transformou na árvore; por causa desse poder transformador, os Tenetehara passaram a usar a pintura corporal em seus rituais, em específico os grafismos pretos que ajudam na passagem para a vida adulta (NEVES; CARDOSO, 2015).

Nas observações em campo desta pesquisa, foi identificado que os desenhos são criados de forma livre, diretamente no suporte humano, tendo como base as crenças relacionadas aos "espíritos" de quem se deixa pintar e na relação entre os "dois mundos" - o real e o não-real. Assim, na sociedade Tenetehara existe um processo dialético "práxis-ideologia-práxis", na qual a ideologia assume "uma posição 'sobrenatural', através dos mitos, das cerimônias e da vida religiosa desse povo" (ZANNONI, 1999, p. 15).

Neste entendimento é possível dividir a mitologia Tenetehara em três narrativas: cosmológica (sem nenhuma identificação temporal), cultural (referente às figuras míticas, ao surgimento da agricultura e rituais, entre outros) e comportamental (referente ao relacionamento com a natureza e as regras comportamentais da sociedade) (IBIDEM, p. 16). Comumente, as narrativas míticas são significativas para os grupos porque estão ligadas à origem do mundo e a sua forma de enxergá-lo (SAPIEZINSKAS, 2012), podem ser entendidas como cosmovisões que sintetizam o conjunto de crenças relacionadas ao ordenamento sociocultural.

A partir do exposto, serão apresentados agora alguns aspectos relevantes da arte gráfica dos Guajajara, em particular, as pinturas corporais presentes no dia a dia e em seus diferentes rituais. As pinturas cotidianas estão atreladas às questões emocionais dos indígenas - como uma forma de aquisição de força -, às crenças para repelir o mau agouro e mal-estar físico e emocional, bem como à transmissão do sentimento de alegria. Tais questões também se constituem uma prática expressa na pintura corporal do grupo Tembé-Tenetehara, mas sendo primordialmente uma demonstração de afeto entre eles (NEVES; CARDOSO, 2015, p. 65).

No estudo em campo foi possível identificar traços finos, triangulares e hexagonais que se entrelaçam em composições distintas nos rostos, braços e pernas de mulheres e crianças. Ao contrário de alguns grupos indígenas que resguardam seus desenhos sob uma única designação, tais como os Wajãpi ${ }^{11}$ com a arte "kusiwa" e os Kaxinawál2 com os "kene", não foi identificada a utilização de um termo próprio para o repertório gráfico dos Guajajara.

O processo de aplicação dos grafismos no suporte humano é menos rigoroso do que aquele conduzido pela sociedade Tembé-Tenetehara, o qual apresenta restrições de uso para mulheres menstruadas e pessoas com "problemas espirituais", assim como denota a responsabilidade da pintura para determinados membros do grupo (NEVES; CARDOSO, 2015, p. 65). Na sociedade

\footnotetext{
${ }^{11}$ Grupo tupi que habita na região delimitada pelos rios Oiapoque, Jari e Araguari no estado do Amapá (ISA, 2018).

${ }^{12}$ Grupo pano que habita a região transfronteiriça entre Brasil e Peru. No Brasil, eles estão nos estados do Acre e Amazonas (ISA, 2018).
} 
Guajajara, a pintura corporal é realizada por todos da aldeia (crianças, jovens, adultos e anciãos), sem distinção e de acordo com a inciativa e sentimento expresso por cada indivíduo.

Ademais, o processo de aplicação dos grafismos não segue orientações específicas, constituindo, portanto, aspirações e escolhas resguardadas pela tradição criativa herdada de geração a geração e que serve como uma espécie de escudo para a alma. Em campo, não foi identificada a pintura como atividade coletiva, cada indivíduo trabalha em sua composição, mas permite a troca de ideias e compartilhamento de traços com os demais, assim, em um processo conduzido de forma livre e espontânea são criados os motivos decorativos que tendem para a finalidade de contemplação.

Para a aplicação dos grafismos no suporte humano são utilizados instrumentos fabricados com fibras e sementes vegetais como o talo da palha de coqueiro e o chumaço do algodão nativo transformados em pincéis que, mergulhados em um recipiente com os pigmentos armazenados, traçam os desenhos na pele sem esboços ou moldes. É oportuno exemplificar esse enredamento com a Figura 02 que apresenta o registro da pintura facial de uma criança Guajajara, realizado na aldeia Zutiwa.

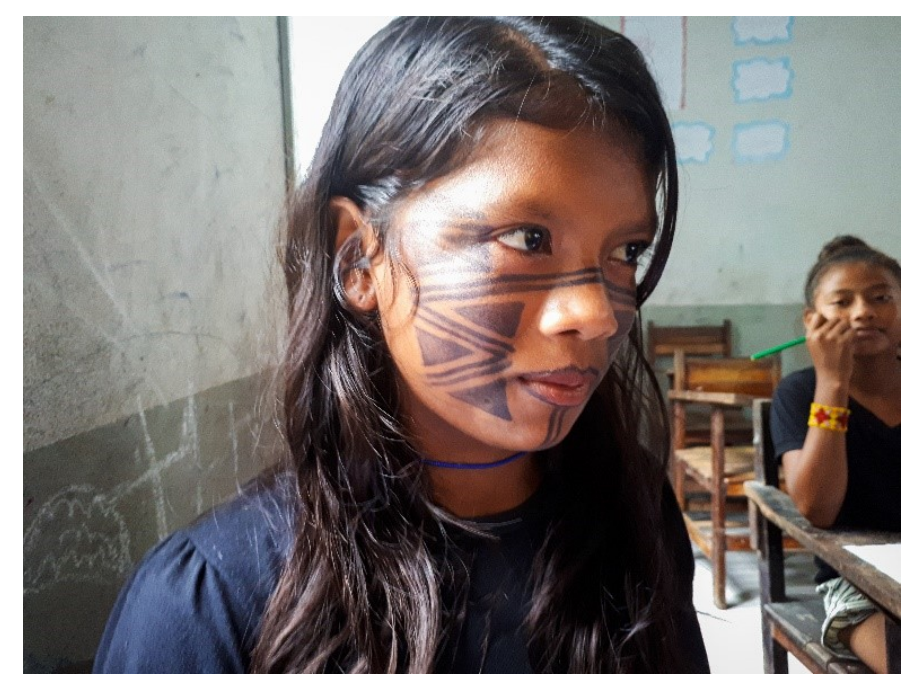

Figura 2 - Menina guajajara com pintura facial cotidiana que mostra os motivos inspirados no couro do jabuti. Fonte: Arquivo da pesquisa em campo (2019).

A Figura 02 evidencia uma composição geométrica que representa o casco do jabuti, presente nas combinações gráficas dos Guajajara que, em sua maioria, são inspiradas na biodiversidade como a pele da jiboia e onça. No contexto da etnologia e mitologia amazônicas, o corpo humano pode ser visto como "lugar de confrontação entre humanidade e animalidade" e ainda como o "[...] instrumento fundamental de expressão do sujeito e ao mesmo tempo o objeto por excelência, aquilo que se dá a ver a outrem", e é por isso que essa "objetivação máxima dos corpos" expressa pela exibição ritual, grafismos e demais adornos, é ao mesmo tempo sua "máxima animalização" (VIVEIRO DE CASTRO, 2002, p. 301).

No interior da arte amazônica, as linhas que compõem os desenhos chamam a atenção para o que conecta e não para o que separa corpos e seres distintos, "é uma arte do entre-dois", interligando os seres humanos e animais "pela qualidade de possuírem desenhos", além de apontar lados visíveis e invisíveis e díades complementares como o homem e mulher, ser humano e espírito; assim, antes de sua forma é desenhada a relação que os conecta e constitui (SEVERI; LAGROU, 2013, p. 14-15).

Em uma perspectiva histórica, a sociedade Tenetehara conserva o ideário de "trocas e reposições" reportado no imaginário das primeiras comunidades de caçadores-coletores e agricultores de floresta, identificando uma estrutura de "duplo sobrenatural" dentro do universo de trocas entre o homem e a natureza (ZANNONI, 1999, p. 13). Com base nas notas de campo, infere-se que as 
pinturas dos Guajajara representam "força e conexão" com a natureza e elas se tornam mais frequentes com a proximidade de suas festas e rituais tradicionais como a Festa da Menina-Moça (Wyrau'haw) ou Festa do Moqueado e a Festa do Rapaz, rituais de iniciação da vida adulta e compromissos sociais com o cacicado e casamento.

A boa colheita e os aniversários dos mais velhos também são celebrados em festas e rituais que envolvem pinturas corporais e utilização de adornos com plumagens e as miçangas que compõem a nova materialidade do grupo. As pinturas elaboradas em rituais e festas marcam as metamorfoses corporais e sociais que os Guajajara passam ao longo da vida. No que tange a Festa da MeninaMoça, os Tenetehara chamam de (Wyrau'haw) o momento da passagem das meninas para a idade adulta, esse tipo de evento é notadamente a comunicação entre o plano empírico e o plano dos encantados (OLIVEIRA, 2019).

Para o ritual, os Guajajara ostentam dois tipos de padrão de pintura, o que forma os motivos gráficos e o que apresenta coberturas densas escuras (oriundas da aplicação do jenipapo que deixa um tom azulado escuro, quase negro) em extensões no antebraço, canela, rosto e palma das mãos. Em alguns momentos os braços e pernas são completamente cobertos pela nódoa do jenipapo em festas e momentos especiais, que alguns indígenas dizem trazer força dos ancestrais. A Figura 03 apresenta o registro dos motivos decorativos usados na Festa da Menina-Moça.

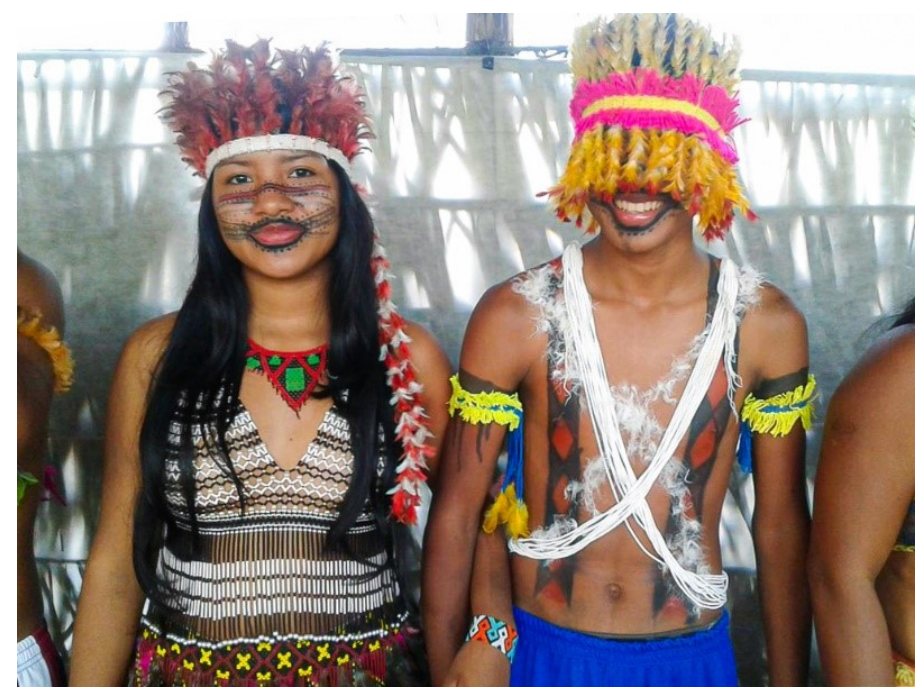

Figura 3 - Crianças guajajara na Festa da Menina-Moça. Fonte: Arquivo da pesquisa em campo (2019).

O uso semiótico do corpo para representações da identidade pessoal e na circulação de valores sociais (TURNER, 1995), evidencia que, na ênfase ameríndia, ele é lugar de uma "perspectiva diferenciante, deve ser maximamente diferenciado para exprimi-la completamente" (VIVEIRO DE CASTRO, 2002, p. 302). Neste sentido, existe a possibilidade de considerar, em sua totalidade, as imagens e grafismos ameríndios como "instrumentos perceptivos" que implicam em operações mentais sustentadas por uma ontologia na qual a "transformabilidade" das formas e dos corpos ocupa um lugar central, assim, o uso dos grafismos e da pintura corporal é percebido em relação ao suporte (LAGROU, 2013, p. 68-69).

No que tange os Guajajara, os grafismos aplicados em seus corpos, no cotidiano e em rituais, seguem a lógica da fabricação do corpo, com distintos procedimentos formais para que a intervenção ritual seja eficaz. Por fim, nas notas em campo, foi registrado o relato de um artesão da aldeia Zutiwa, o qual sintetiza que "[...] a pintura corporal é ritual sagrado, para os indígenas, sendo também fortalecimento espiritual e demonstração de força da etnia", neste sentido, o estilo formal da arte gráfica permite refletir com mais atenção sobre a estruturação de seu mundo, no qual infere 
Lagrou (2013), é possível interpretar a centralidade da transformação e das metamorfoses no mundo amazônico.

\section{Considerações finais}

A pintura corporal exerce magia de quem a faz e em quem é mosaico dessa experiência; assim, foi possível perceber o sentimento que permeia a arte dos talentosos indígenas que detêm essa prática. As visualidades dos Guajajara os reafirmam como reconhecedores de suas potencialidades culturais, bem como sabedores da importância da manutenção de suas tradições e resguardo de sua cosmologia para a sobrevivência do seu povo e território, não somente a sobrevivência no sentido econômico pautado no oportuno caráter de divulgar, mas na manutenção de suas práticas existenciais ancestrais.

Seus marcadores exemplificados neste estudo são capazes de apontar seus atributos que se compõe de um vasto acervo de práticas culturais, produção de artefatos, saberes e experiências de manejo e cultivo agrícola e culinário que, além de representar formas milenares de arte e cultura, também são identidade de um povo, tecida em uma linha com a ancestralidade. Riqueza genuína e de uma valorização dos povos originários e das formas de vida dos povos indígenas Guajajara do Maranhão.

Podemos inferir que os indígenas Guajajara não concebem cultura nem como um sistema de signos e significados criados pelos grupos sociais somente, como cita Botelho (2001), que inclui conhecimento, crenças, arte, leis, costumes ou qualquer outra capacidade ou hábitos adquiridos pelo homem como membro de uma sociedade como apregoa Laraia (2001), nem pelo entrelaçamento de teia (GEERTZ, 2012) ou ainda como assevera Rubim (2007) ser entendida apenas para além do patrimônio e da arte, nas suas dimensões simbólicas, cidadã e de desenvolvimento. Mas a concebe como elemento de sobrevivência de seu povo, na vida e na morte, e mesmo tendo que resistir contra uma inoportuna política pública que insiste em não os ouvir para programar melhorias de convivialidade que são em sua maioria prejudiciais à manutenção de sua cultura.

Os grafismos dos ameríndios da etnia de que trata esse estudo trouxe à tona uma narrativa do povo Guajajara por intermédio de seus traços gráficos marcados na pele, que permitem o reconhecimento da identidade cultural desse grupo como um conceito que traduz o seu coletivo geral e que mesmo permeado de representações de outros povos se concebe em uma identidade única. Neste ínterim, é oportuno ressaltar que, as representações gráficas aplicadas em suportes humanos por meio da pintura revelam a questão da corporalidade como central na vida indígena e está vinculada a um sistema de relações entre corpos nas quais a humanidade de um corpo não é inata, mas deve ser construída culturalmente e de modo contínuo (VELTHEM, 2010).

Foi possível destacar e conhecer quatro padrões distintos para a composição dos motivos decorativos para o corpo e que representam desde sentimentos, alegorias festivas, celebrações cosmológicas e entretenimento. A riqueza do registro realizado pelos próprios indígenas Guajajara, também se traduz em limite da pesquisa, que deixou de poder enquadrar essas amostras pelos olhares de um profissional da fotografia. Bem como, as inúmeras nuances que permeiam a vida nos territórios indígenas que nos desnudam de protocolos rígidos da sociedade contemporânea e nos colocam frente ao desconhecido dos povos indígenas. Por tudo dito, pesquisas de cunho qualitativas trazem muito do olhar do pesquisador e sinalizam quão distantes estamos dos desvelamentos sociais que sociedades tradicionais e indígenas têm a nos demonstrar.

Agradecimentos:

Ao povo Guajajara por dizer tanto com alguns traços e cores. 


\section{Referências}

BARROS, A. L. Sinalizadores de empreendedorismo indígena para o turismo: a ressignificação da cultura do povo Guajajara no espaço vivido da aldeia Zutiwa/MA-Brasil. Tese (Doutorado em Turismo e Hotelaria) - Universidade do vale do Itajaí, Balneário Camboriú, 2019.

BETIM, F. Dois indígenas Guajajara são assassinados no Maranhão em escalada de violência na zona. 2019. Disponível em: https://brasil.elpais.com/brasil/2019-12-08/dois-indigenas-guajajarasao-assassinados-no-maranhao-em-escalada-de-conflito-na-zona.html?rel=listapoyo. Acesso em 20 jan. 2021.

BOTELHO, I. Dimensões da cultura e políticas públicas. São Paulo em Perspectiva, São Paulo, v.15, n.2, p. 73-83, 2001. Doi: https://doi.org/10.1590/S0102-88392001000200011

FREIRE, J. R. B. Tradição oral e memória indígena: a canoa do tempo. In: SALOMÃO, Jayme. América: descoberta ou invenção. $4^{\circ}$ Colóquio UERJ. Rio de Janeiro: Imago, 1992, p. 1-28.

GEERTZ, C. A interpretação das culturas. Rio de Janeiro: LTC, 2012.

LAGROU, E. Arte ou Artefato? Agência e significado nas artes indígenas. PROA Revista de Antropologia e Arte, [s.1.], v. 1, n. 2, 2010, p. 01. Disponível em: https://www.ufrgs.br/ppgas/portal/arquivos/orientacoes/LAGROU_Els._2010.pdf. Acesso em: 20 jan. 2021.

. Uma reflexão sobre uma arte perspectivista. In: SEVERI, C.; LAGROU, E. (Orgs.). Quimeras em diálogo: grafismo e figuração na arte indígena. Rio de Janeiro: Editora 7 Letras, 2013, p. 68-69.

LAGROU, E.; VELTHEM, L. H. V. As artes indígenas: olhares cruzados. Revista Brasileira de Informação Bibliográfica em Ciências Sociais - BIB, São Paulo, n. 87, p.133-156, 2018. Disponível em: $\quad$ https://www.anpocs.com/index.php/bib-pt/bib-87/11596-as-artes-indigenas-olharescruzados/file. Acesso em: 20 jan. 2021

LARAIA, R. de B. Cultura: um conceito antropológico. 14 ed. Rio de Janeiro: Jorge Zahar, 2001.

MARTÍN, G.; ASÓN, I. Comunicação gráfica entre os indígenas do Nordeste do Brasil. Revista Nordestina de História do Brasil, Cachoeira, vol. 1, n. 1, p. 46-65 2019. Doi: https://doi.org/10.17648/2596-0334-v1i1-991

NEVES, I. dos S.; CARDOSO, A. S. P. Patrimônio cultural Tembé-Tenetehara: terra indígena alto rio Guamá. Belém: IPHAN, 2015.

NEVES, I.; CORRÊA, M. Sentidos da Pele Aikewára. Belém: Ed. da Unama, 2011.

OLIVEIRA, A. C. A. Wyrau'haw: A Festa da Menina-Moça do povo indígena Tenetehara/Guajajara. Amazônica: revista de antropologia, [s.1.], v.11, 2019, p. 874. Doi: http://dx.doi.org/10.18542/amazonica.v11i2.6591

PESSIS, AM.; GUIDON, N. Registros rupestres e caracterização das etnias pré-históricas. In: VIDAL, L. (Org.). Grafismo indígena: estudos de antropologia estética. São Paulo: Studio Nobel: FAPESP: Editora da Universidade de São Paulo, 2000, p. 19-34. 
Instituto Socioambiental - ISA. Povos Indígenas no Brasil. Huni Kuin (Kaninawá), 2018. Disponível em: https://pib.socioambiental.org/pt/Povo:Huni_Kuin_(Kaxinaw\%C3\%A1). Acesso em 8 jan. 2021.

. Wajãpi, 2018. Disponível em: https://pib.socioambiental.org/pt/Povo:Waj\%C3\%A3pi. Acesso em 8 jan. 2021.

. Guajajara, 2020. Disponível em: https://pib.socioambiental.org/pt/Povo:Guajajara . Acesso em 10 jan. 2021.

RUBIM, A. A. A. Políticas Culturais; entre o possível e o impossível. In: NUSSBAUMER, G. M. (Org.). Teorias e Políticas da Cultura. Salvador: EDUFBA, 2007, p. 33-47.

SÁ, M. J. R. de; SILVA, M. das G. Etnoecologia indígena: saberes e fazeres culturais no cotidiano Tentehar. Tellus, Campo Grande, n. 33, p. 91-113, 2017. Doi: https://doi.org/10.20435/tellus.v17i33.447

SAPIEZINSKAS, A. Como se constrói um artesão: negociações de significado e uma 'cara nova' para as 'coisas da vovó. Horizontes Antropológicos, Porto Alegre, vol. 18, n. 38, p. 133-158, 2012. Doi: https://doi.org/10.1590/S0104-71832012000200006

SCRODER, P. Guajajara. In: Associação Carlo Ubbiali; Instituto EKOS; Instituto Socioambiental (Org.). Os índios do Maranhão. O Maranhão dos índios (Livro eletrônico). Disponível em: https://acervo.socioambiental.org/sites/default/files/documents/0QD00106.pdf. Acesso $20 \mathrm{fev}$. 2021.

SEVERI, C.; LAGROU, E. (Orgs.). Quimeras em diálogo: grafismo e figuração na arte indígena. Rio de Janeiro: Editora 7 Letras, 2013.

SILVA, T. F. da. História da língua Tenetehára: contribuição aos estudos histórico-comparativos sobre a diversificação da família linguística tupí-guaraní do tronco tupi. Tese (Doutorado em Linguística) - Universidade de Brasília, Brasília, 2010.

TOCHETTO, F. B. Possibilidades de interpretação do conteúdo simbólico da arte gráfica Guarani. Estudos Ibero-Americanos, [s.1.], vol. 22, n. 1, p. 27-46, 1996. Doi: https://doi.org/10.15448/1980864X.1996.1.28774

TURNER, T. Social body and embodied subject: bodiliness, subjectivity, and sociality among the Kayapo. Cultural Anthropology, [s.1.], vol. 10, n. 2, p. 143-170, 1995. Disponível em: https://www.jstor.org/stable/656331?seq=1. Acesso em 20 jan. 2021.

VELTHEM, L. H. V. Artes Indígenas: notas sobre a lógica dos corpos e dos artefatos. Textos escolhidos de cultura e arte populares, Rio de Janeiro, vol. 07, n. 1, p. 55-65, 2010. Doi: https://doi.org/10.12957/tecap.2010.12052

VIDAL, L. Ornamentação corporal entre grupos indígenas. In: FUNARTE - Instituto Nacional de Artes Plásticas. Arte e Corpo: pintura sobre a pele e adornos de povos indígenas brasileiros. Rio de Janeiro: FUNARTE: INAP, 1985, p. 14-19.

. Iconografia e grafismos indígenas, uma introdução. In: VIDAL, L. (Org.). Grafismo indígena: estudos de antropologia estética. São Paulo: Studio Nobel: FAPESP: Editora da Universidade de São Paulo, 2000, p. 13-19. 
VIVEIROS DE CASTRO, Eduardo. A inconstância da alma selvagem - e outros ensaios de antropologia. São Paulo: Cosac \& Naify, 2002.

WAGLEY, C.; GALVÃO, E. Os indios Tenetehara (uma cultura em transição). Rio de Janeiro: Ministério da Educação e Cultura, 1961.

ZANNONI, C. Mito e sociedade Tenetehara: notas preliminares para análise. Cadernos de Campo, n. 5, 1999. Disponível em: https://periodicos.fclar.unesp.br/cadernos/article/view/10312 . Acesso em: 20 jan. 2021. 